\title{
A COMPARISON OF THE METABOLIC AND CIRCULATORY EFFECTS OF EPINEPHRINE, NOR-EPINEPHRINE AND INSULIN HYPO- GLYCEMIA WITH OBSERVATIONS ON THE INFLUENCE OF AUTONOMIC BLOCKING AGENTS ${ }^{1}$
}

\author{
By R. J. DiSALVO,² WALTER L. BLOOM, ALBERT A. BRUST, ROBERT W. \\ FERGUSON, AND EUGENE B. FERRIS \\ (From the Department of Internal Medicine, Emory University School of Medicine, and the \\ Grady Memorial Hospital, Atlanta, Ga.)
}

(Submitted for publication September 20, 1955; accepted January 16, 1956)

Interest in adrenal medullary function has been revived in recent years by the demonstration that the adrenal medulla produces two hormones, epinephrine and nor-epinephrine. Nor-epinephrine, which is also produced by adrenergic nerves (1), differs in its chemical structure from epinephrine by the absence of an $\mathrm{N}$-methyl group, and is the probable precursor of epinephrine. The observation by Goldenberg, Faber, Alston, and Chargaff (2) that adrenal medullary extract from cattle (natural epinephrine, U.S.P.) contained up to 18 per cent nor-epinephrine was confirmed by Tullar (3) and Auerbach and Angell (4). Subsequently, nor-epinephrine was found in varying proportions in the adrenal medullary extracts of several mammalian species, including man, and it has been shown that the majority of pheochromocytomas contain larger amounts of nor-epinephrine than of epinephrine (5).

Although the cardiovascular effects of these hormones in man have been well established (6), there are few studies concerning their comparative metabolic effects. It is highly probable that in many of the early studies of the circulatory and metabolic effects of epinephrine, mixtures which contained varying proportions of nor-epinephrine were used, since it was demonstrated in 1948 that adrenal medullary extract from cattle produced a rise in blood sugar in the rabbit comparable to that obtained with a mixture of 75 per cent epinephrine and 25 per cent nor-epinephrine, rather than that obtained with pure epinephrine (7).

The similarity of the responses which occur during insulin hypoglycemia to those produced

1 The work described in this paper was aided in part by grants from the Life Insurance Medical Research Fund and the Georgia Heart Association.

2 Present address: Veterans Administration Hospital, Cincinnati, Ohio. by the administration of epinephrine, and the presence of increased amounts of epinephrine in the blood and urine during hypoglycemia $(8,9)$, have led to the general belief that increased adrenal medullary secretion during insulin hypoglycemia is in part responsible for the symptoms produced and for spontaneous recovery of the blood glucose level. This is further suggested by the observation in rats that a rise in blood lactic acid, similar to that which results from the administration of epinephrine, also occurs during insulin hypoglycemia. The lactic acidemia induced by hypoglycemia can be prevented by adrenal medullectomy (10).

This study was undertaken 1) to evaluate certain metabolic and circulatory effects of pure epinephrine and nor-epinephrine in man and to compare these effects with those induced by insulin hypoglycemia, and 2) to determine the effect of an autonomic blocking agent on certain circulatory and metabolic changes which occur during insulin hypoglycemia in order to throw light on the mechanisms involved in these changes.

\section{MATERIAL AND METHODS}

All subjects were free of metabolic or cardiovascular disease and fasted for at least 12 hours without physical activity or sedation. Throughout the study, blood pressure was measured at one-minute intervals by the auscultatory method. Pulse rate was measured every five minutes and electrocardiograms were obtained at frequent intervals. Lactic acid and glucose (as total reducing substance) were determined in duplicate in copper tungstate filtrates prepared from venous blood. Glucose was measured by the Nelson method (11) and lactic acid by a modification of the Barker-Summerson method (12).

Solutions of pure 1-epinephrine and 1-nor-epinephrine ${ }^{8}$ were made from the powdered form and ascorbic acid

${ }^{3}$ Supplied through the courtesy of Dr. M. L. Tainter, Winthrop-Stearns, Ind. 
TABLE I

The effect of epinephrine on blood lactic acid and blood glucose

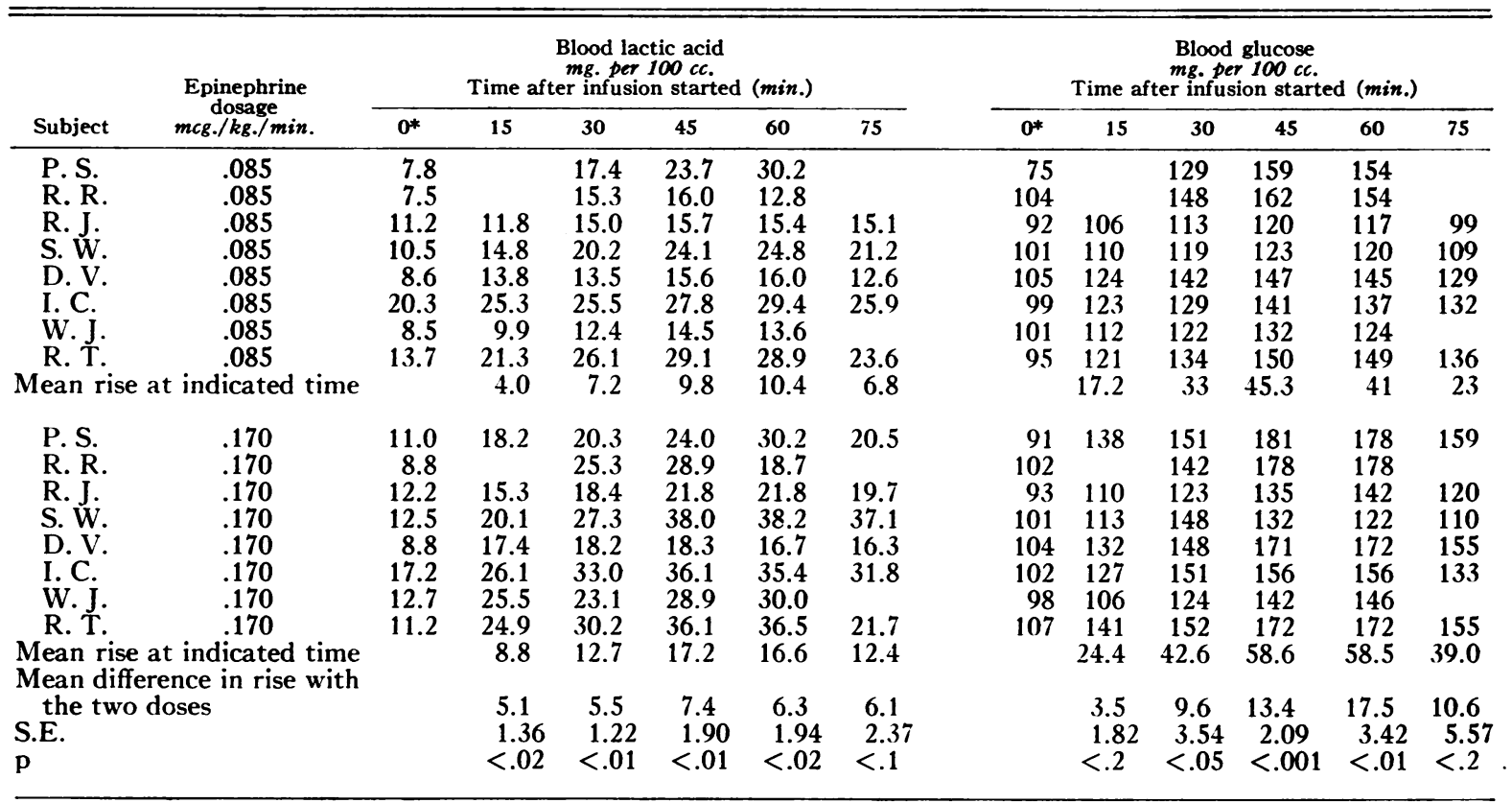

* The values in $\mathbf{0}$ column are the mean of two determinations obtained during the control period.

was added as a preservative. Appropriate dilutions with saline were made from these stock solutions.

Following a one-hour control period, $.085 \mathrm{mcg}$. per $\mathrm{kg}$. per min. of epinephrine was administered intravenously with a Bowman constant infusion pump to eight subjects for a 50-minute period. Two blood samples were obtained during the control period and single samples at 15-minutes intervals during and after the infusion period. In order to evaluate dose responses, the infusions were repeated in the same subjects on a subsequent day under similar conditions except that the quantity of epinephrine was doubled $(.170 \mathrm{mcg}$. per $\mathrm{kg}$. per min.).4

The effects of nor-epinephrine $.170 \mathrm{mcg}$. per $\mathrm{kg}$. per min. were studied in a similar manner in four subjects. Double this dosage of nor-epinephrine was attempted, but had to be discontinued because of severe side effects.

In order to determine whether the circulatory and metabolic changes induced by administered epinephrine were affected by an autonomic blocking agent, hexamethonium ${ }^{5}$ (100 mg.) was administered intravenously to three subjects before beginning an infusion of $.085 \mathrm{mcg}$. per $\mathrm{kg}$. per min. of epinephrine. Three additional sub-

4 The doses of epinephrine and nor-epinephrine originally planned for this study were $0.10 \mathrm{mcg}$. per $\mathrm{kg}$. per min. and $0.20 \mathrm{mcg}$. per $\mathrm{kg}$. per min. Subsequent to completion of the study constant weighing and calculation errors were discovered which necessitated correction to the accurate dosage values.

5 Hexameton chloride, supplied through the courtesy of Burroughs-Wellcome and Co. jects were given a rapid intravenous injection of $400 \mathrm{mg}$. of tetraethylammonium chloride ${ }^{6}$ (TEAC) before and again during the infusion.

Insulin hypoglycemia was induced in five subjects with 15 units of regular insulin intravenously after a one-hour control period. Hypoglycemia was terminated with intravenous glucose $\mathbf{5 0}$ minutes later. Four blood samples were obtained during the control period, and single samples at ten-minute intervals during the insulin period, and at 15-minute intervals after glucose was begun. On a subsequent day, insulin hypoglycemia was again induced in the same subjects following the administration of $100 \mathrm{mg}$. of hexamethonium intravenously during the last ten minutes of the control period.

\section{RESULTS}

Striking differences in both the circulatory and metabolic effects of epinephrine and nor-epinephrine were observed. Epinephrine produced an increase in the pulse pressure accompanied by tachycardia and $\mathrm{T}$-wave changes in the electrocardiogram. These circulatory changes were accompanied by an increase in blood glucose and lactic acid as summarized in Table I. Neither hexamethonium nor TEAC had any effect on either

${ }^{6}$ Etamon chloride supplied by Parke, Davis and Company, through the courtesy of Dr. E. C. Vonder Heide. 
TABLE II

The effect of nor-epinephrine on blood lactic acid and blood glucose

\begin{tabular}{|c|c|c|c|c|c|c|c|c|c|c|c|c|c|}
\hline \multirow[b]{2}{*}{ Subject } & \multirow{2}{*}{$\begin{array}{c}\text { Nor- } \\
\text { epinephrine } \\
\text { dosage } \\
m c g . / \mathrm{kg} . / \min .\end{array}$} & \multicolumn{6}{|c|}{$\begin{array}{c}\text { Blood lactic acid } \\
\text { Time after infusion started (min.) }\end{array}$} & \multicolumn{6}{|c|}{$\begin{array}{c}\text { Blood glucose } \\
\text { Time after infusion started (min.) }\end{array}$} \\
\hline & & 0 & 15 & 30 & 45 & 60 & 75 & o & 15 & 30 & 45 & 60 & 75 \\
\hline $\begin{array}{l}\text { J.H. } \\
\text { M. M. } \\
\text { B. S. } \\
\text { J. B. }\end{array}$ & $\begin{array}{l}.170 \\
.170 \\
.170 \\
.170\end{array}$ & $\begin{array}{r}7.9 \\
16.1 \\
21.3 \\
8.3\end{array}$ & $\begin{array}{r}9.6 \\
16.1 \\
14.7 \\
8.6\end{array}$ & $\begin{array}{r}9.4 \\
11.1 \\
10.2 \\
8.4\end{array}$ & $\begin{array}{r}9.2 \\
12.0 \\
9.8 \\
8.5\end{array}$ & $\begin{array}{r}10.4 \\
10.8 \\
9.3 \\
8.5\end{array}$ & $\begin{array}{r}10.2 \\
10.6 \\
9.3 \\
8.2\end{array}$ & $\begin{array}{r}77 \\
109 \\
103 \\
115\end{array}$ & $\begin{array}{r}99 \\
131 \\
119 \\
120\end{array}$ & $\begin{array}{r}84 \\
135 \\
127 \\
127\end{array}$ & $\begin{array}{r}82 \\
141 \\
122 \\
124\end{array}$ & $\begin{array}{r}77 \\
121 \\
111 \\
120\end{array}$ & $\begin{array}{r}75 \\
105 \\
99 \\
113\end{array}$ \\
\hline $\begin{array}{l}\text { Mean } \\
\text { Mean rise } \\
\text { S.E. } \\
\text { p }\end{array}$ & & 13.4 & $\begin{array}{c}12.3 \\
-1.2 \\
1.86 \\
<.6\end{array}$ & $\begin{aligned} & 9.8 \\
&- 3.6 \\
& 2.86 \\
&<.3\end{aligned}$ & $\begin{array}{c}9.9 \\
-3.5 \\
2.90 \\
<.4\end{array}$ & $\begin{array}{c}9.8 \\
-3.6 \\
3.23 \\
<.4\end{array}$ & $\begin{aligned} & 9.6 \\
&- 3.8 \\
& 3.18 \\
&<.4\end{aligned}$ & 101 & $\begin{array}{r}117 \\
16 \\
4.94 \\
<.05\end{array}$ & $\begin{array}{r}118 \\
17 \\
4.61 \\
<.05\end{array}$ & $\begin{array}{c}117 \\
16 \\
6.02 \\
<.1\end{array}$ & $\begin{array}{l}107 \\
\quad 6 \\
2.53 \\
<.1\end{array}$ & $\begin{array}{c}98 \\
-3 \\
2.66 \\
<.4\end{array}$ \\
\hline
\end{tabular}

the circulatory or metabolic changes induced by infused epinephrine.

Nor-epinephrine produced a rise in both systolic and diastolic blood pressure, associated with bradycardia. There was a slight rise in blood glucose but no change in lactic acid (Table II). The effects of TEAC on the blood pressure changes induced by nor-epinephrine are presented in another report (13).

Circulatory and metabolic changes similar to those which occurred during the infusion of epinephrine were observed during insulin hypoglycemia. These changes were prevented by hexamethonium, as shown in Table III.

\section{Epinephrine}

The effect of epinephrine on blood pressure and pulse rate in eight subjects is shown in Figure 1 . The infusion of $.085 \mathrm{mcg}$. per $\mathrm{kg}$. per min. resulted in a mean increase in systolic pressure of $10 \mathrm{~mm} . \mathrm{Hg}$ and a mean fall in diastolic pressure of $13 \mathrm{~mm}$. $\mathrm{Hg}$; the mean pulse rate rose from 84 per minute to 97 per minute. Infusion of double this amount of epinephrine $(.170 \mathrm{mcg}$. per $\mathrm{kg}$. per min.) produced a mean increase of $19 \mathrm{~mm} . \mathrm{Hg}$ in systolic pressure and a mean decrease of $12 \mathrm{~mm}$. $\mathrm{Hg}$ in diastolic pressure, with a rise in pulse rate from 86 to 107 per minute. When the infusion

TABLE III

Effect of hexamethonium on response of blood lactic acid and blood glucose to insulin hypoglycemia

\begin{tabular}{|c|c|c|c|c|c|c|c|c|c|c|c|c|c|c|}
\hline \multirow[b]{2}{*}{ Subject } & \multicolumn{8}{|c|}{$\begin{array}{c}\text { Blood lactic acid } \\
m g . \text { per } 100 c c . \\
\text { Time after insulin }(\text { min.) }\end{array}$} & \multicolumn{6}{|c|}{$\begin{array}{c}\text { Blood glucose } \\
\text { mg. per } 100 c c \\
\text { Time after insulin }(\text { min.) }\end{array}$} \\
\hline & $\mathbf{0}$ & 10 & 20 & 30 & 40 & 50 & 65 & 80 & $\mathbf{0}$ & 10 & 20 & 30 & 40 & 50 \\
\hline \multicolumn{15}{|c|}{ Insulin 15 units I.V. } \\
\hline $\begin{array}{l}\text { A. C. } \\
\text { J.S. } \\
\text { M. N. } \\
\text { R. J. } \\
\text { B. W. }\end{array}$ & $\begin{array}{r}14.8 \\
10.1 \\
15.2 \\
9.0 \\
8.4\end{array}$ & $\begin{array}{r}12.6 \\
12.9 \\
13.8 \\
9.1 \\
10.5\end{array}$ & $\begin{array}{r}15.8 \\
14.2 \\
17.1 \\
10.1 \\
9.2\end{array}$ & $\begin{array}{l}17.7 \\
13.5 \\
16.4 \\
10.4 \\
10.0\end{array}$ & $\begin{array}{l}25.3 \\
15.2 \\
16.6 \\
10.1 \\
11.7\end{array}$ & $\begin{array}{l}29.9 \\
20.1 \\
20.7 \\
19.0 \\
13.7\end{array}$ & $\begin{array}{l}27.1 \\
20.4 \\
19.0 \\
15.4 \\
13.2\end{array}$ & $\begin{array}{l}24.9 \\
19.8 \\
17.0 \\
17.5 \\
15.2\end{array}$ & $\begin{array}{r}123 \\
87 \\
97 \\
85 \\
87\end{array}$ & $\begin{array}{r}105 \\
81 \\
79 \\
91 \\
93\end{array}$ & $\begin{array}{l}71 \\
63 \\
47 \\
63 \\
73\end{array}$ & $\begin{array}{l}53 \\
60 \\
35 \\
50 \\
47\end{array}$ & $\begin{array}{l}47 \\
48 \\
33 \\
42 \\
34\end{array}$ & $\begin{array}{l}62 \\
59 \\
39 \\
52 \\
48\end{array}$ \\
\hline \multicolumn{2}{|c|}{$\begin{array}{l}\text { Mean change at } \\
\text { indicated time }\end{array}$} & +0.26 & +1.77 & +2.10 & +4.29 & +9.19 & +7.51 & +7.37 & & -6.0 & -32.4 & -46.8 & -55.0 & -43.8 \\
\hline \multicolumn{15}{|c|}{ Hexamethonium $100 \mathrm{mg} . \mathrm{I.V} .+$ insulin 15 units I.V. } \\
\hline $\begin{array}{l}\text { A. C. } \\
\text { J.S. } \\
\text { M. N. } \\
\text { R. J. } \\
\text { B. W. }\end{array}$ & $\begin{array}{r}13.2 \\
15.1 \\
13.6 \\
12.0 \\
9.5\end{array}$ & $\begin{array}{l}12.6 \\
13.7 \\
13.5 \\
12.4 \\
10.0\end{array}$ & $\begin{array}{r}13.7 \\
12.5 \\
14.2 \\
17.8 \\
9.4\end{array}$ & $\begin{array}{l}16.8 \\
12.6 \\
18.8 \\
19.5 \\
10.2\end{array}$ & $\begin{array}{l}18.3 \\
13.3 \\
15.9 \\
13.1 \\
10.0\end{array}$ & $\begin{array}{r}18.0 \\
18.5 \\
14.5 \\
16.1 \\
6.7\end{array}$ & $\begin{array}{r}19.9 \\
16.8 \\
15.7 \\
12.7 \\
9.0\end{array}$ & $\begin{array}{l}23.8 \\
17.6 \\
16.4 \\
14.8 \\
11.1\end{array}$ & $\begin{array}{r}98 \\
91 \\
95 \\
92 \\
121\end{array}$ & $\begin{array}{r}75 \\
81 \\
92 \\
90 \\
114\end{array}$ & $\begin{array}{l}38 \\
48 \\
55 \\
69 \\
84\end{array}$ & $\begin{array}{l}20 \\
37 \\
34 \\
55 \\
62\end{array}$ & $\begin{array}{l}22 \\
32 \\
23 \\
46 \\
49\end{array}$ & $\begin{array}{l}21 \\
31 \\
22 \\
43 \\
41\end{array}$ \\
\hline \multicolumn{2}{|c|}{$\begin{array}{l}\text { Mean change at } \\
\text { indicated time } \\
\text { Mean diff. in } \\
\text { change with }\end{array}$} & -0.25 & +0.87 & +2.90 & +1.44 & +2.09 & +2.13 & +4.08 & & -9.0 & -40.6 & -57.8 & -65 & -67.8 \\
\hline $\begin{array}{l}\text { and wit } \\
\text { S.E. }\end{array}$ & it $\mathrm{C} 6$ & $\begin{array}{c}+0.51 \\
1.09 \\
<.7\end{array}$ & $\begin{array}{c}+0.90 \\
1.83 \\
<.7\end{array}$ & $\begin{array}{c}-0.81 \\
2.06 \\
<.8\end{array}$ & $\begin{array}{c}+2.84 \\
1.48 \\
<.2\end{array}$ & $\begin{array}{r}+7.10 \\
0.98 \\
<.01\end{array}$ & $\begin{array}{r}+5.38 \\
1.09 \\
<.01\end{array}$ & $\begin{array}{c}+3.29 \\
1.69 \\
<.2\end{array}$ & & $\begin{array}{c}+3.0 \\
\quad 4.76 \\
<.6\end{array}$ & $\begin{array}{r}+8.0 \\
6.0 \\
<.3\end{array}$ & $\begin{array}{c}+11.0 \\
5.26 \\
<.2\end{array}$ & $\begin{array}{c}+10.0 \\
4.09 \\
<.1\end{array}$ & $\begin{array}{r}+24.0 \\
5.30 \\
<.02\end{array}$ \\
\hline
\end{tabular}




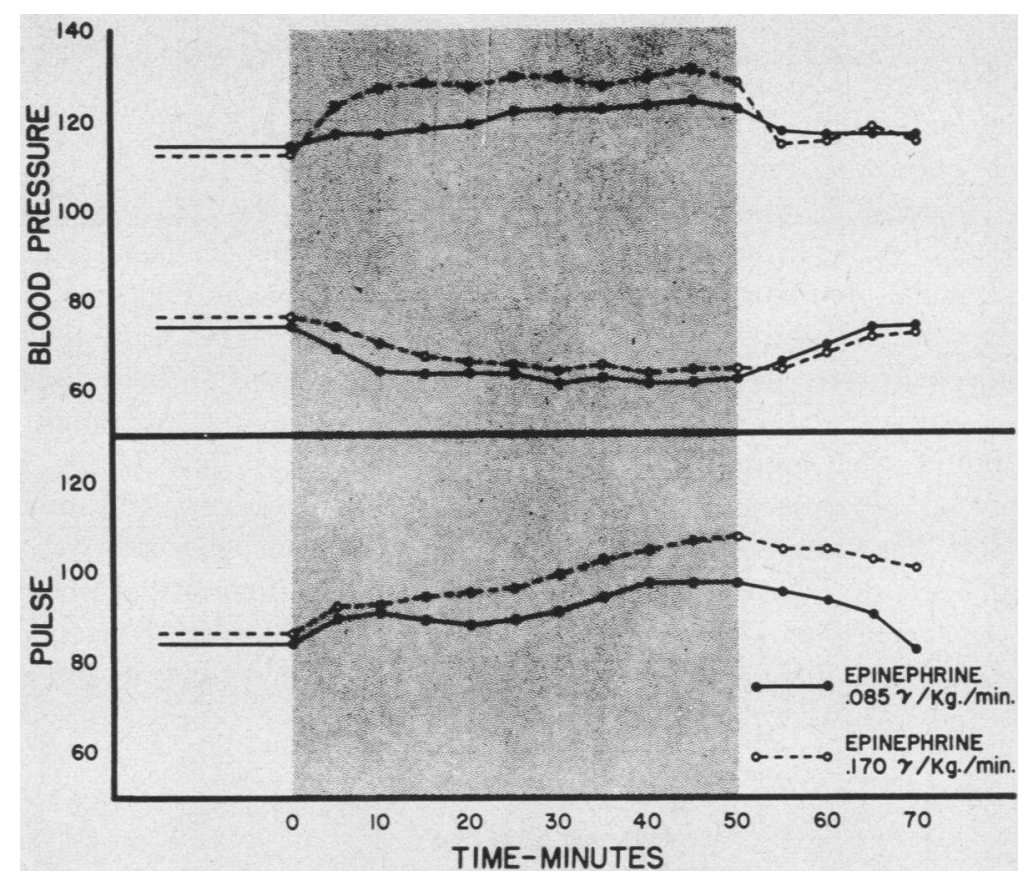

Fig. 1. The Mean Blood Pressure (mm. Hg) and Pulse Rate (per minute) Responses to Epinephrine in Eight Subjects Who Receiven .085 MCG. PER KG. PER MIN. ONE DAy AND .170 MCG. PER KG. PER MIN. ON A SUbSEQUENT DAY

The shaded area represents the infusion period.

was stopped, the blood pressure and pulse promptly returned to control values.

The electrocardiograms taken on six subjects during the infusion showed a decreased amplitude of the $T$-waves in four and inversion of the $\mathrm{T}$-waves in two; the QT interval was prolonged in five. These changes were more marked with the larger dose, and disappeared in from thirty to sixty minutes after the infusion was discontinued.

The effects of epinephrine on blood glucose and lactic acid are shown in Figure 2. The peak rise in glucose occurred 45 minutes after the infusion was started; a mean rise of $45 \mathrm{mg}$. per cent was observed with $.085 \mathrm{mcg}$. per $\mathrm{kg}$. per min. and 59 mg. per cent with the larger dose. Comparisons of the rise in glucose above individual control values at the two-dose levels show a significant difference at 45 and 60 minutes, indicating a dose response relationship with respect to blood glucose.

The maximum rise in blood lactic acid occurred ten minutes after the infusion of $.085 \mathrm{mcg}$. per $\mathrm{kg}$. per min. of epinephrine was ended and five min- utes before the infusion with the larger dose was ended. The smaller dose produced a mean increase of $9.8 \mathrm{mg}$. per cent above the control value, while the large dose resulted in a mean increase of $17.2 \mathrm{mg}$. per cent above the control value. The differences between the elevations of lactic acid obtained with the two doses of epinephrine are statistically significant at the $15,30,45$ and 60 minute periods after the start of the infusion, and suggest a dose response relationship with respect to lactic acid.

Hexamethonium and TEAC had no effect on the circulatory or metabolic effects of epinephrine. In the three subjects who received hexamethonium prior to the infusion, blood glucose (average) increased $62 \mathrm{mg}$. per cent above the control level, and blood lactic acid $10.8 \mathrm{mg}$. per cent. Similar results were obtained in the three subjects who received TEAC before and during the infusion.

\section{Nor-epinephrine}

In Figure 3 are shown the mean changes in blood pressure and pulse rate in the four sub- 
jects who received $.170 \mathrm{mcg}$. per $\mathrm{kg}$. per min. of nor-epinephrine. The mean rise in systolic pressure was $38 \mathrm{~mm} . \mathrm{Hg}$ and $26 \mathrm{~mm}$. $\mathrm{Hg}$ rise in diastolic pressure. The pulse rate decreased from 83 to 63 per minute. Changes in the $\mathrm{T}$-waves and QT intervals seen with epinephrine did not occur. In one subject, nodal premature contractions appeared shortly after the infusion was begun but disappeared spontaneously after minutes of infusion.

Within a few minutes after beginning an infusion of $.340 \mathrm{mcg}$. per $\mathrm{kg}$. per min. of nor-epinephrine in these subjects, the mean blood pressure rose from a control level of $108 / 63 \mathrm{~mm}$. $\mathrm{Hg}$ to $185 / 115 \mathrm{~mm}$. $\mathrm{Hg}$, an increase of $77 \mathrm{~mm}$. systolic and $52 \mathrm{~mm}$. diastolic. Simultaneously, severe throbbing headache and a sense of tightness in the chest developed, and the infusion was discontinued. The blood pressure rapidly returned to normal, although the headache persisted for as long as thirty minutes.

The effects of $.170 \mathrm{mcg}$. per $\mathrm{kg}$. per min. of nor-epinephrine on blood glucose and lactic acid are also shown in Figure 2 and Table II. The effects of the larger dose could not be evaluated because the infusion was discontinued after only a few minutes. A maximum mean increase in blood glucose of only $17 \mathrm{mg}$. per cent above the control value occurred 30 minutes after the infusion was begun; this rise was not significant and was only one-fourth that obtained with a similar dose of epinephrine. Nor-epinephrine had no effect on the blood lactic acid in any of the four subjects.

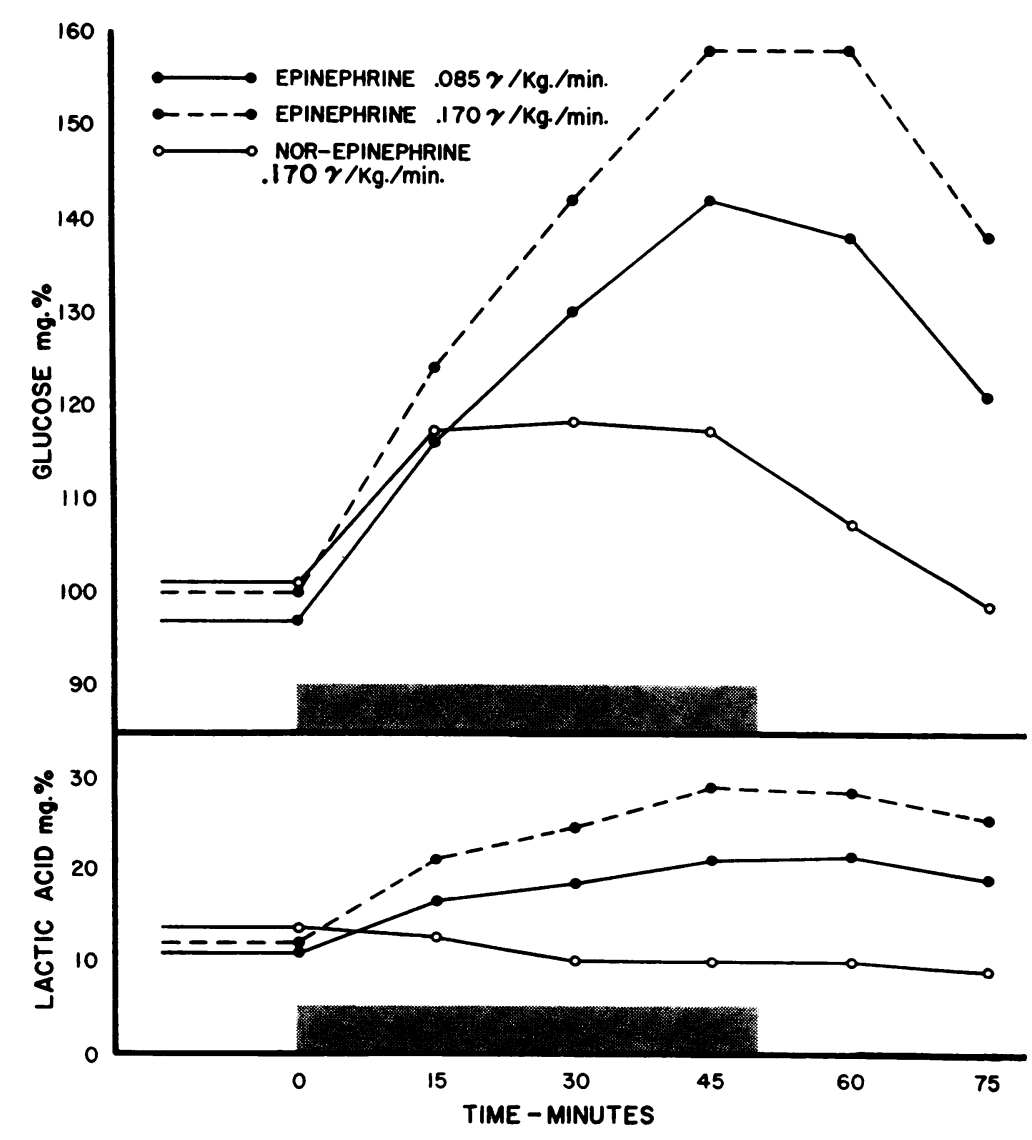

Fig. 2. Mean Values of the Response of the Blood Glucose and Lactic Acid during the Infusions of Epinephrine in the Eight SubJects Shown in Figure 1

In addition mean glucose and lactic acid responses during the infusion of nor-epinephrine are pictured. Again the shaded areas represent the infusion period. 


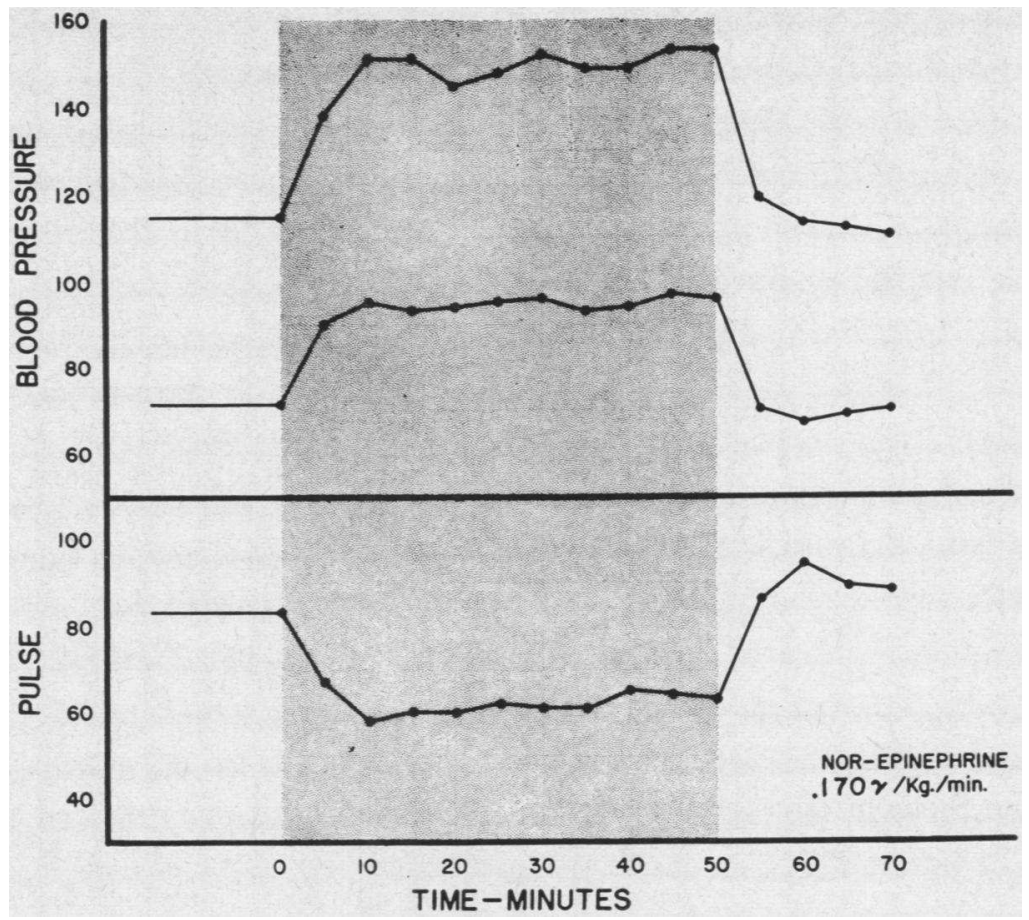

Fig. 3. Mean Blood Pressure and Pulse Rate Responses in Four SubJects Who Received .170 mCG. PER KG. PER MIN. OF NOR-EPINEPHRINe

The mean blood glucose and lactic acid responses in these subjects are depicted in Figure 2.

\section{Insulin hypoglycemia}

The circulatory changes which occurred during insulin hypoglycemia and the effect of hexamethonium on these changes are shown in Figure 4. Between 20 and 30 minutes after the administration of insulin, profuse sweating, hunger sensations and mild palpitation occurred in all subjects; simultaneous with these symptoms, the systolic blood pressure began to rise, the diastolic began to fall, and the heart rate increased. The $T$-wave in the electrocardiogram decreased in amplitude or inverted. The maximum changes in blood pressure and pulse were observed a few minutes before glucose was given, and pulse increased from 75 to 90 per minute. The circulatory changes and symptoms disappeared, rapidly after the hypoglycemia was terminated; however, the $\mathrm{T}$-wave changes persisted for as long as one hour.

During and following the intravenous administration of hexamethonium, all subjects developed signs of autonomic blockade as manifested by dryness of the mouth. dilatation and fixation of the pupils to light, absence of sweating, and increase in the pulse rate and a slight fall in blood pressure. Following the administration of insulin and during the hypoglycemic period the signs of autonomic blockade were maintained. The blood pressure, which continued to fall and reached its lowest level at the time when widening of the pulse pressure occurred with insulin alone, showed a mean maximum fall of $28 \mathrm{~mm}$. $\mathrm{Hg}$ systolic and $20 \mathrm{~mm}$. $\mathrm{Hg}$ diastolic from the control level. There was no further increase in pulse rate from that produced by the hexamethonium. Changes in the electrocardiogram similar to those observed with insulin alone also occurred. Hunger sensations were not abolished but were milder.

In Figure 5 are shown the metabolic changes which occurred during insulin hypoglycemia together with the effect of hexamethonium on these changes. Following insulin alone, the mean glucose level showed a steady fall during the first $\mathbf{4 0}$ minutes of the hypoglycemic period and then rose spontaneously before intravenous glucose was given. Blood lactic acid rose to $20.7 \mathrm{mg}$. per cent 
(a significant rise from the control value) at the same time the spontaneous rise in glucose occurred.

After autonomic blockade with hexamethonium, insulin produced a greater hypoglycemic effect. During the last ten minutes of the insulin period, the blood glucose continued to fall, in marked contrast to the spontaneous rise observed at this time with insulin alone. Despite the further fall in glucose, the mean maximum rise in lactic acid during the hypoglycemic period was only $2.0 \mathrm{mg}$. per cent above the control value. As shown in Table III, individual variations in the lactic acid responses following blockade with hexamethonium showed considerable latitude in comparison with the changes in blood glucose, which were more consistent.

Changes in blood glucose similar to those observed in the present study with insulin alone and insulin with hexamethonium have been reported in man by Laurence and Stacey (14) and by Schachter in dogs (15).

\section{DISCUSSION}

In the first published report on the comparative hemodynamic effects of epinephrine and nor-epinephrine in man Goldenberg, Pines, Baldwin, Greene, and Roh (6) demonstrated that the pressor properties of these hormones result from different mechanisms. Epinephrine in doses sufficient to affect the blood pressure causes overall vasodilatation, a decrease in the peripheral resistance, a striking increase in the cardiac output and an increase in the heart rate due to direct cardiac stimulation. As a result, the systolic blood pressure becomes elevated but the diastolic pressure remains unchanged or falls. In contrast, norepinephrine causes overall vasoconstriction with consequent increase in the peripheral resistance, and no change in the cardiac output. Thus elevation of both systolic and diastolic pressure occurs. The heart rate is slowed by nor-epinephrine, presumably because of increased vagal tone, since the bradycardia may be abolished by atropine.

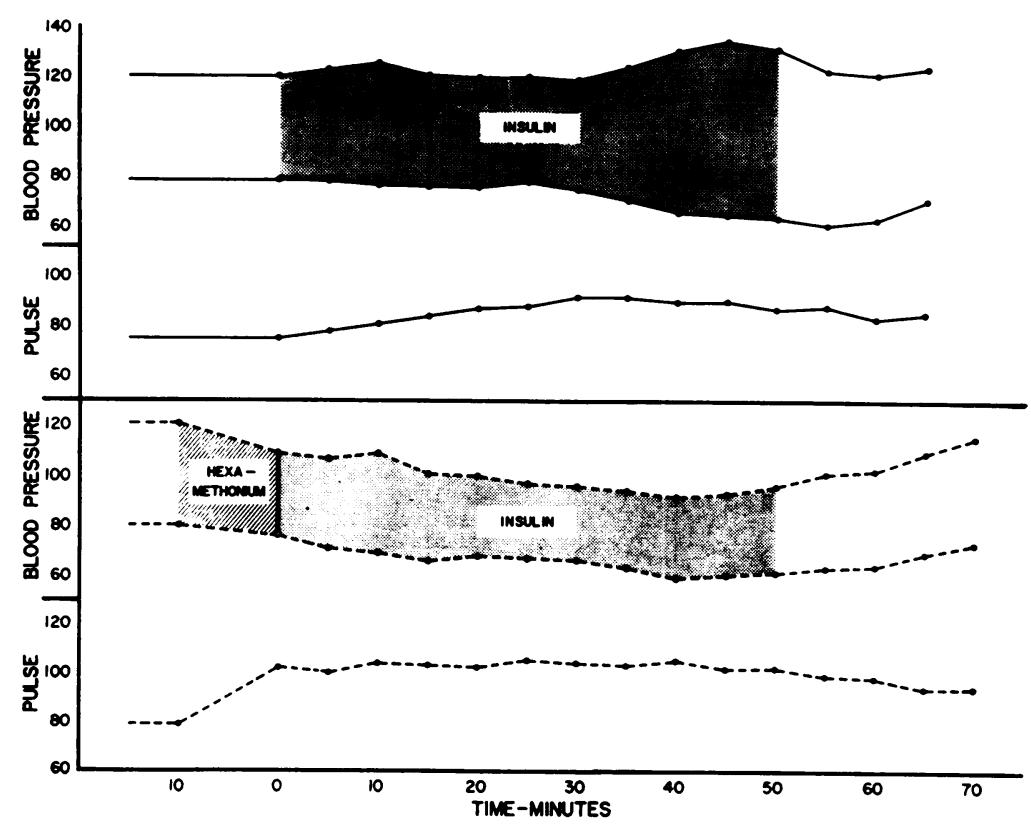

Fig. 4. The Mean Blood Pressure and Pulse Rate Changes which Occurred in Five Subjects during Insulin Hypoglycemia are Depicted on the Upper Portion of the Figure. In the Lower Portion are the Changes Observed in These Same Subjects when the Same Dose of Insulin (15 units) was Preceded by Autonomic Blockade with HexaMETHONIUM (100 MG. INTRAVENOUSLY)

The shaded "insulin" areas indicate the period from injection of insulin to the termination of hypoglycemia by the administration of glucose. 


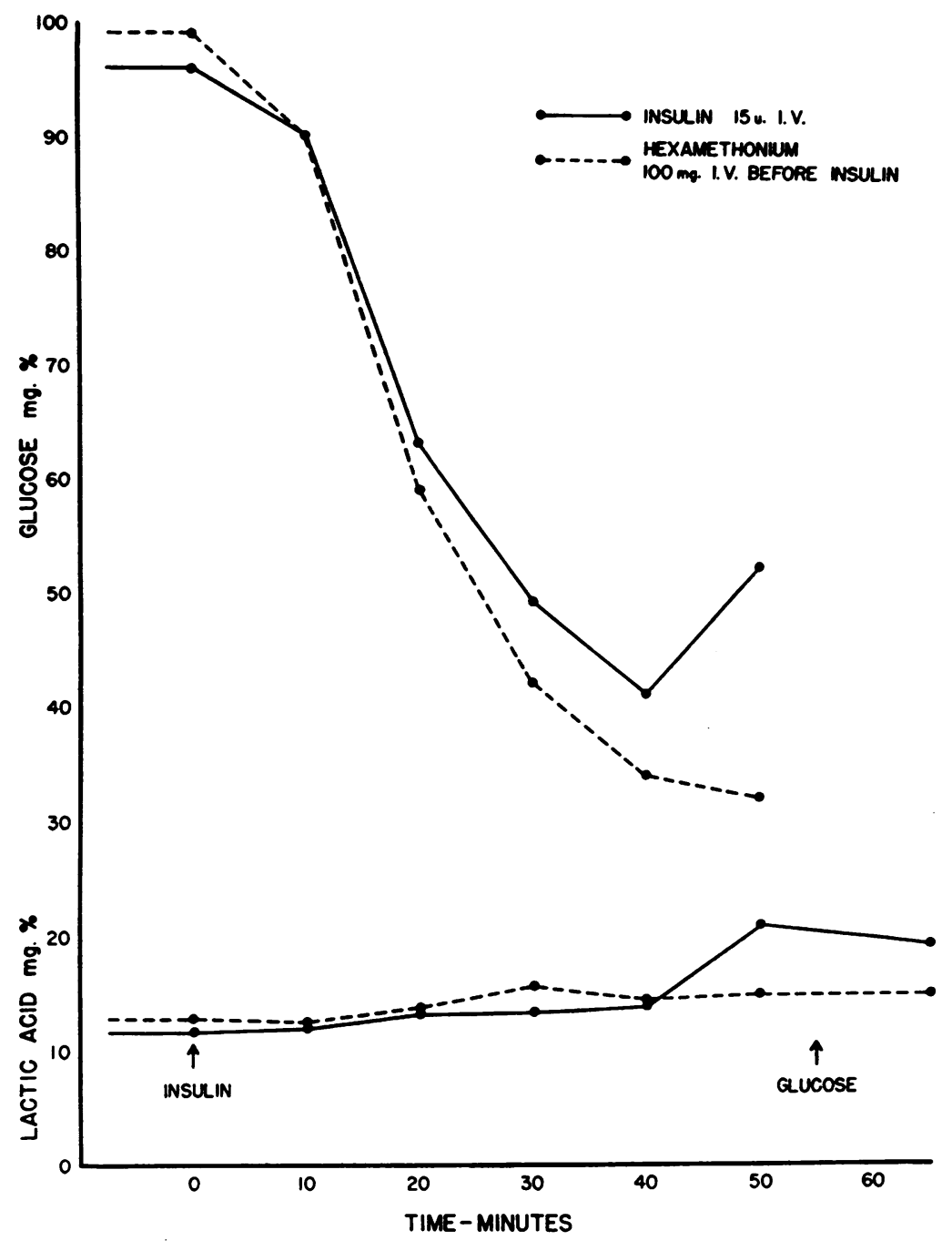

Fig. 5. The Effect of Hexamethonium on the Blood Glucose and Lactic Acid Response to Insulin in the Same Subjects Depicted in FIGURE 4

Note that after hexamethonium the hypoglycemic effect was greater, the blood glucose failed to rise at 50 minutes and the blood lactic acid rise was inhibited.

Electrocardiographic changes similar to those observed with epinephrine in this study have been reported by other investigators $(16,17)$ and may be related to changes in serum potassium or to the effects of this hormone on the myocardium (18, 19).

The circulatory and metabolic changes produced by infused epinephrine are quite similar to those observed here during insulin hypoglycemia, suggesting that adrenal medullary secretion of epinephrine is stimulated during hypoglycemia in man. Rise of the blood lactic acid and spontaneous recovery of the blood sugar curve are thereby accounted for on the basis of an induced epinephrinemia. The release of epinephrine in significant amounts from the adrenal medulla appears to be related to the degree of hypoglycemia. To judge from the blood lactic acid responses here presented, the secretion of epinephrine has begun when the blood glucose concentration reaches levels of approximately $50 \mathrm{mg}$. per cent.

In the rat, mild insulin hypoglycemia does not 
affect the blood lactic acid; however, there is a very definite increase during moderate or severe hypoglycemia. In the adrenal demedullated rat, lactic acid does not increase during hypoglycemia and the degree of hypoglycemia produced by a given dose of insulin is greater than in the intact animal (10). Although the blood glucose level ultimately recovers, the recovery period is considerably prolonged in comparison with that of the intact animal. Quantitatively, the changes which occurred during insulin hypoglycemia in the subjects in the present study were approximately the same as those observed during the first fifteen minutes of the intravenous administration of $.170 \mathrm{mcg}$. per $\mathrm{kg}$. per min. of epinephrine (Figures 2 and 5 ).

Both hexamethonium and TEAC block transmission through autonomic ganglia. Hexamethonium was given before insulin because the blockade persists for well over one hour, whereas that produced by TEAC is much shorter in duration. The prevention by hexamethonium of the epinephrine-like changes induced by insulin hypoglycemia may be interpreted as indicating inhibition of adrenal medullary secretion of epinephrine. since neither hexamethonium nor TEAC affected the responses to administered epinephrine. The most likely site of block is the medulla itself. since it may be considered a modified ganglion and is supplied by pre-ganglionic fibers.

Billington, Paton, Reynolds, and Sherlock (20) in similar studies used intramuscular hexamethonium bromide ( $1 \mathrm{mg}$. per $\mathrm{Kg}$.) and intravenous insulin (0.1 unit per $\mathrm{kg}$.) given simultaneously. They were unable to prevent arterial lactic acidemia and did not observe either enhancement of hypoglycemia or failure of spontaneous recovery of the blood sugar. However, they did note inhibition of the expected rise in hepatic glucose output and splanchnic oxygen consumption and thereby postulated a partial block of epinephrine release by hexamethonium. It appears likely that the smaller dose of hexamethonium they employed or slower absorption from the intramuscular injection (whereas insulin was given intravenously at the same time) produced an incomplete block or allowed epinephrine to be released from the adrenal medulla before effective hexamethonium blockade was achieved.
The similarity of the electrocardiographic changes following insulin alone and insulin preceded by hexamethonium are of interest. The fact that these changes were not affected following hexamethonium despite the prevention of other changes during hypoglycemia suggests that epinephrine was not responsible and that some other mechanism may be involved.

The release of epinephrine by the adrenal medulla as an immediate or emergency response to moderate or severe hypoglycemia in man seems demonstrated by our data. The further fall in blood glucose and inhibition of the lactic acid response by hexamethonium indicate that this emergency response was prevented by blockade of the adrenal medulla. It is probable that ultimate recovery of the blood glucose level by other mechanisms would have occurred had the hypoglycemia not been terminated. It has been suggested that one such mechanism may be a direct glycogenolytic response of the liver to hypoglycemia (21): this may be the major factor which determines spontaneous recovery of the glucose level (22).

The observation that the blood lactic acid levels rise in response to epinephrine but are not influenced by nor-epinephrine may be of aid in evaluating the relative amount of epinephrine production by pheochromocytomas.

\section{SLMMARY AND CONCLUSIONS}

1. A comparative study of the effects of epinephrine and nor-epinephrine on the blood pressure, pulse rate, electrocardiogram, blood glucose and lactic acid is presented.

2. Epinephrine influences the circulation mainly through its cardiac effects, while norepinephrine acts mainly on the peripheral vessels.

3. Epinephrine induces a significant rise in blood glucose and lactic acid while nor-epinephrine does not affect these significantly.

4. The reported circulatory and metabolic changes induced by insulin hypoglycemia are qualitatively similar to these seen with the administration of epinephrine.

5. Whereas the circulatory and metabolic effects of administered epinephrine are not influenced by ganglionic blockade of the autonomic nervous system with hexamethonium or TEAC, these same effects are prevented by hexametho- 
nium followed by insulin hypoglycemia, suggesting that the main pharmacologic action of these agents on the adrenal medulla is a blocking one.

6. The electrocardiographic effects induced by epinephrine, nor-epinephrine and insulin hypoglycemia are presented.

7. Blood lactic acid levels may be of aid in recognizing the presence of pheochromocytomas which produce mainly epinephrine.

\section{REFERENCES}

1. von Euler, U. S., Identification of the sympathomimetic ergone in adrenergic nerves of cattle (sympathin N) with levo-noradrenalin. Acta physiol. Scandinav., 1948, 16, 63.

2. Goldenberg, M., Faber, M., Alston, E. J., and Chargaff, E. C., Evidence for the occurrence of nor-epinephrine in the adrenal medulla. Science, 1949, 109, 534.

3. Tullar, B. F., The separation of 1-arterenol from natural U.S.P. epinephrine. Science, 1949, 109, 536.

4. Auerbach, M. E., and Angell, E., The determination of arterenol in epinephrine. Science, 1949, 109, 537.

5. Goldenberg, M., Serlin, I., Edwards, T., and Rapport, M. M., Chemical screening methods for the diagnosis of pheochromocytoma. I. Nor-epinephrine and epinephrine in human urine. Am. J. Med., 1954, 16, 310.

6. Goldenberg, M., Pines, K. L., Baldwin, E., Greene, D. G., and Roh, C. E., The hemodynamic response of man to nor-epinephrine and epinephrine and its relation to the problem of hypertension. Am. J. Med., 1948, 5, 792.

7. Holtz, P., Schumann, H. J., Langenbeck, W., and Le Blanc, H., Uber das Vorkommen von Arterenol in den Nebennieren. Naturwiss, 1948, 35, 191.

8. Cannon, W. B., McIver, M. A., and Bliss, S. W., Studies on the conditions of activity in endocrine glands. XIII. A sympathetic and adrenal mechanism for mobilizing sugar in hypoglycemia. Am. J. Physiol., 1924, 69, 46.

9. von Euler, U. S., and Luft, R., Effect of insulin on urinary excretion of adrenalin and noradrenalin.
Studies in ten healthy subjects and in six cases of acromegaly. Metabolism, 1952, 1, 528.

10. Bloom, W. L., and Russell, J. A., To be published.

11. Nelson, N., A photometric adaptation of the Somogyi method for the determination of glucose. J. Biol. Chem., 1944, 153, 375.

12. Hawk, P. B., Oser, B. L., and Summerson, W. H., Practical Physiological Chemistry, 12th ed. Philadelphia, The Blakiston Co., 1947.

13. Brust, A. A., DiSalvo, R. J., Evan, J. D., and Ferris, E. B., The effect of tetraethylammonium chloride on the pressor response to epinephrine and norepinephrine. In preparation for publication.

14. Laurence, D. R., and Stacey, R. S., Effect of hexamethonium on the response to insulin in animals and man. Brit. J. Pharmacol., 1952, 7, 255.

15. Schachter, M., Hexamethonium and insulin hypoglycaemia. J. Physiol., 1951, 115, 206.

16. Clough, H. D., Studies on epinephrine. III. Effect of epinephrine on the electrocardiograms of patients with "irritable heart." Arch. Int. Med., 1919, 24. 284.

17. Katz, L. N., Hamburger, W. W., and Lev, M., The diagnostic value of epinephrine in angina pectoris. Am. Heart J., 1932, 7, 371.

18. Parrish, A. E., Sugar, S. J. N., and Fazekas, J. F., A relationship between electrocardiographic changes and hypokalemia in insulin-induced hypoglycemia. Am. Heart J., 1952, 43, 815.

19. Raab, W. R., Hormonal and Neurogenic Cardiovascular Disorders; Endocrine and Neuro-endocrine Factors in Pathogenesis and Treatment. Baltimore, Williams and Wilkins Company, 1953.

20. Billington, B. P., Paton, A., Reynolds, T. B., and Sherlock, S., The effect of hexamethonium bromide on the circulatory and metabolic response to insulin hypoglycemia in man. J. Lab. \& Clin. Med., 1954, 43, 880.

21. Lazarus, S. S., and Volk, B. W., Studies on hypoglycemia responsiveness. Metabolism, 1953, 2, 500.

22. Engel, F. L., and Scott, J. L., The insulin-glucose tolerance test. A modified procedure for the detection of hypoglycemia unresponsiveness in pituitary and adrenal insufficiency. J. Clin. Invest., 1950, 29, 151. 